\title{
EDUCAÇÃO PROFISSIONAL PARA OS JOVENS NAS POLÍTICAS EDUCACIONAIS DA 1a DÉCADA DO SÉCULO XXI
}

\author{
E. R. S. LIMA*, F. N. SILVA e L. L. S. SILVA \\ Instituto Federal de Educação, Ciência e Tecnologia do Rio Grande de Norte \\ erika_limma@hotmail.com*
}

Artigo submetido em julho/2015 e aceito em julho/2015

DOI: $10.15628 /$ holos.2015.3185

\section{RESUMO}

No Brasil são considerados jovens os cidadãos e cidadãs com idade compreendida entre os 15 e os 29 anos. São sujeitos de direitos e deveres e devem ter sua autonomia e identidade respeitadas. Na sociedade brasileira a maioria dos jovens das classes menos favorecidas economicamente já assume responsabilidades ligadas à provisão do próprio domicílio. Assim sendo, são vários os jovens que não concluem a Educação Básica, ou tem negada a possibilidade de ingressar no Ensino Superior. Para esses jovens poderiam ser oferecidas condições e oportunidades de acesso à Educação Profissional articulada à Educação Básica. É nesse sentido que se discute, neste artigo, a Educação Profissional para os jovens no Brasil, com ênfase nas políticas educacionais, articuladas à Educação Básica desenvolvidas na 1a década do século XXI. Para tanto, foi realizada uma pesquisa documental nos principais documentos orientadores das políticas e dos programas voltados para Educação Profissional e também, uma pesquisa bibliografia, embasada principalmente em: Oliveira (2012) Moura (2012), Venturi e Abramo (2000) e Frigotto, Ciavatta e Ramos (2005). Fez-se ainda, um levantamento sobre matrículas de jovens na Educação Profissional, nos Censos Escolares de 2000 a 2010, disponibilizados no site do Instituto Nacional de Estudos e Pesquisas Educacionais Anísio Teixeira (INEP). Os programas de Educação Profissional articulados à Educação Básica encontrados no período em estudo são políticas públicas de educação, trabalho e qualificação para os jovens brasileiros, especificamente, para aqueles que estão em situação de vulnerabilidade socioeconômica.

PALAVRAS-CHAVE: Políticas Educacionais, Educação Profissional, Jovens Brasileiros.

\section{PROFESSIONAL EDUCATION FOR YOUNG PEOPLE IN THE EDUCATION POLICIES OF THE FIRST DECADE OF THE $21^{\text {st }}$ CENTURY}

\begin{abstract}
In Brazil citizens between 15 and 29 years old are regarded as young people. They have rights and duties; their identity and autonomy must be respected. In Brazilian society, most young people from lower classes already take over responsibilities linked to the provision of their own homes. Therefore, many young people do not complete Basic Education, or are denied the possibility of entering higher education. Consequently, they should be offered conditions and opportunities of access to Professional Education articulated to Basic Education. Thus, the article discusses Professional Education for young people in Brazil, with emphasis in education policies linked to Basic Education developed in the first decade of the 21st century. The following procedures were conducted: a documentary research
\end{abstract}

involving the main documents guiding the policies and programs related to Professional Education; a bibliographic research, mainly based on Oliveira (2012), Moura (2012), Venturi and Abramo (2000), Frigotto, Ciavatta and Ramos (2005); and a survey on the enrollments of young people in Professional Education, in the School Censuses from 2000 to 2010, available on the website of the Instituto Nacional de Estudos e Pesquisas Educacionais Anísio Teixeira (The National Institute for Educational Studies and Research Anísio Teixeira, INEP). The Professional Education programs articulated to Basic Education found in the period under study are public policies for education, work and qualification for young Brazilians, specifically to the ones who are in situation of socioeconomic vulnerability.

KEYWORDS: Education Policies, Professional Education, Young Brazilians. 


\section{INTRODUÇÃO}

No Brasil, a Educação Profissional tem seu início marcado por um caráter assistencialista, voltado para as classes menos favorecidas, com o objetivo de ensinar um ofício. Esta característica originou um marco de dualidade na educação brasileira, pois, a Educação Profissional foi historicamente voltada para as classes populares enquanto o Ensino Superior era destinado à elite. Essa realidade persistiu e chegou na $1^{\text {a }}$ década do século XXI, apesar de atualmente ser menos perceptível. Ao longo da história houve várias modificações na Educação Profissional, desde sua concepção de formação à forma de como esteve e está organizada.

A Educação Profissional no início do século XXI passou a ser um discurso central nos governos como àquela que deveria ser destinada, principalmente, aos jovens para formação e preparação para ingresso no mercado de trabalho, vista como garantia de desenvolvimento e crescimento econômico do país. Contudo, a qualificação para o trabalho não é um processo rápido e nem de fácil controle social e/ou estatal. Por essa razão, tê-la como garantia de desenvolvimento e crescimento econômico é no mínimo temerário em sociedades marcadamente capitalistas.

Os jovens são cidadãos e cidadãs com idade compreendida entre os 15 e os 29 anos. Constitucionalmente são sujeitos de direitos e deveres e devem ter sua autonomia e identidade respeitadas. Existem diversos grupos de jovens, esses variam de acordo com sua origem social ou nível de escolaridade entre outros aspectos selecionados para tal finalidade.

Dentre os grupos há os jovens oriundos de famílias economicamente privilegiadas que prorrogam sua iniciação profissional, dedicando maior tempo possível à escolarização e a uma melhor preparação educacional, buscando uma colocação melhor no mercado de trabalho. Estes jovens são sustentados economicamente por suas famílias até concluírem os estudos necessários à produção de suas existências. (AQUINO, 2009). Enquanto outros jovens, oriundos de famílias desfavorecidas economicamente, assumem responsabilidades ligadas à provisão do próprio domicílio. Por isso, no Brasil são vários os jovens que não concluem a Educação Básica, ou tem negada a possibilidade de ingressar no Ensino Superior.

Isso decore da falta de oportunidade para o estudo e o trabalho na sociedade capitalista e ganham sentidos diferentes conforme a renda da família dos jovens. Sendo assim, quanto maior a renda maior a possibilidade de escolarização dos jovens. Contribuindo, dessa forma, para a permanência das desigualdades sociais, pois, quanto maior a escolarização maiores são as chances de encontrar postos no mercado de trabalhos que ofereçam melhores salários.

Neste contexto, existe o dilema entre garantir aos jovens um tempo maior na escola para uma boa escolarização, o que impede sua inserção de forma precoce no mercado de trabalho, e por outro lado, a necessidade dos jovens de trabalhar para garantir suas necessidades materiais.

De acordo com os dados da Pesquisa Nacional de Amostra por Domicílio- Instituto Brasileiro de Geografia e Estatística (PNAD-IBGE, 2001) entre os jovens de 15 a 24 anos no Brasil: 24,7\% só estudavam; $18,7 \%$ estudavam e trabalhavam; $32 \%$ só trabalhavam; 5,2\% estudavam e procuravam emprego; $59 \%$ só procuravam emprego; e 13,5\% não estudavam, não trabalhavam, nem procuravam emprego. 
A taxa média de abandono e reprovação dos jovens no Ensino Médio é de 35,5\%, verificada entre os anos de 2007 e 2009 (BRASIL, 2009). Apenas 48\% dos matriculados estão na faixa etária considerada regular, isto é, se encontram entre 15 e 17 anos. E mais de $40 \%$ das matrículas estão no período noturno, pois são jovens que precisam trabalhar para produzir suas condições materiais de vida no turno diurno. Portanto, para os jovens, que são obrigados pela situação econômica a ingressarem no mercado de trabalho antes de concluírem a Educação Básica, poderiam ser oferecidas oportunidades e condições de acesso à Educação Profissional articulada à Educação Básica, podendo ser ofertada nas modalidades integrada e concomitante nas escolas públicas.

Neste artigo, discute-se a Educação Profissional para os jovens no Brasil, com ênfase nas políticas educacionais, articuladas à Educação Básica desenvolvidas na 1a década do século XXI, a partir das seguintes questões: Quais são os motivos que tem levado os jovens a abandonarem a escola? Qual formação deve ser ofertada aos jovens brasileiros? Quais os programas nacionais de inclusão na Educação Profissional, com vista à escolarização e preparação dos jovens para o trabalho?

Para a elaboração deste artigo realizou-se uma pesquisa documental nos principais documentos orientadores das políticas e dos programas voltados para Educação Profissional e também, uma pesquisa bibliografia, embasada principalmente em: Oliveira (2012) Moura (2012), Venturi e Abramo (2000) e em Frigotto, Ciavatta e Ramos (2005). Fez-se ainda, um levantamento sobre os números das matrículas dos jovens na Educação Profissional, nos Censos Escolares de 2000 a 2010, disponibilizados no site do Instituto Nacional de Estudos e Pesquisas Educacionais Anísio Teixeira (INEP).

Para uma melhor organização do texto o artigo está estruturado da seguinte forma: primeiro discute-se as políticas educacionais para a juventude na $1^{\text {a }}$ década do século XXI. Em seguida, são apresentados os programas para a Educação Profissional articulados à Educação Básica em desenvolvimento do ano 2000 até o ano de 2010. Por fim, apresenta-se as reflexões finais acerca dos programas de inclusão de jovens na Educação Profissional articulada à Educação Básica.

\section{POLÍTICAS EDUCACIONAIS PARA OS JOVENS NA 1a DÉCADA DO SÉCULO XXI}

Nos ensina Acácia Kuenzer que devemos "disponibilizar aos jovens que vivem do trabalho a nova síntese entre o geral e o particular, entre o lógico e o histórico, entre a teoria e a prática, entre o conhecimento, o trabalho e a cultura (KUENZER, 2002, p. 43-44). Sendo assim, para que essa possibilidade se efetive no mundo atual é necessário que a política, ou melhor as políticas públicas se estruturem com esse direcionamento.

O termo política recebeu vários significados ao longo da história das sociedades, desde a Grécia Antiga, com Platão e Aristóteles, até os dias atuais, com autores como Azevedo (2005, p.05) que conceitua políticas públicas como "materialidade da intervenção do Estado", ou seja, como medidas e procedimentos que indicam a orientação política do Estado para o desenvolvimento de suas ações em todas as dimensões de sua atuação. Assim sendo, pode-se afirmar que as políticas públicas traduzem a intenção do Estado junto à sociedade, assumindo uma forma coletiva de ação. Na compreensão de Bispo dos Santos (2012) essas políticas tornam-se "ações geradas na esfera do 
Estado e que têm como objetivo atingir a sociedade como um todo, ou parte dela." (BISPO DOS SANTOS, 2012, p. 05).

No sentido dado às políticas públicas pelos autores já citados é possível entender que para os jovens no Brasil, como parte da sociedade, deveriam ser planejadas políticas para intervir nas condições de vida desse público específico, pois esses sujeitos são protagonistas sociais, existentes dentro de uma realidade concreta pouco favorável à melhoria das condições de vida dessa população, seja pela falta de educação de qualidade, seja pela falta de políticas de envolvimento cultural e esportivo. Isto é o que mostram os indicadores da educação para os jovens no Brasil.De acordo com Venturi e Abramo (2000, p. 01. grifos do autor):

Durante muito tempo só foram considerados efetivamente "jovens" (como condição social, para além da definição meramente etária) aqueles que podiam viver tal suspensão, proteção e preparação -quase exclusivamente, portanto, os jovens das classes médias e altas, caracterizados principalmente por sua condição de estudante. Os jovens das classes populares, tendo de trabalhar e interrompendo os estudos muito cedo, ou a eles nem tendo acesso, ficaram excluídos dessa construção, como se vivessem a juventude em negativo.

De fato, a situação socioeconômica afeta a vida dos jovens, dificultando o acesso à saúde, à educação, ao esporte, ao lazer e a outros direitos que devem ser garantidos pelo Estado. No entanto, sabe-se que a organização da sociedade em classes, implica na desigualdade de distribuição de renda que está relacionada fortemente com a pobreza e à exclusão social; e notadamente, à manutenção dos princípios capitalistas de produção.

Nesse contexto, é preciso verificar quais condições são dadas aos jovens brasileiros e quais medidas concretas estão sendo implementadas, para que os jovens que precisam ingressar cedo no mercado de trabalho não sejam excluídos da Educação Básica? Como descrito por Venturi e Abramo (2000. p. 02):

Entre os $42 \%$ que já pararam de estudar; apenas $1 \%$ o fez por ter chegado à formação completa, de 3 o grau ( $2 \%$ interromperam o curso superior, $6 \%$ estão cursando) e apenas $30 \%$ concluíram o ensino médio ( $18 \%$ o abandonaram) formação que, dada a proporção da faixa etária com 18 anos ou mais, deveria ter sido atingida por $69 \%$. Cerca de metade dos que pararam de estudar (51\%) o fizeram no máximo ao fim do ensino fundamental, dentre os quais, $12 \%$ sequer ultrapassaram a 4a série. Para os adolescentes (de 15 a 17 anos), embora a condição de estudante esteja mais presente (87\%), é grave constatar que cerca de 1 em cada 8 desses jovens das regiões metropolitanas já está fora da escola.

A evasão dos jovens da escola é consequência, na maioria dos casos, da necessidade dos jovens das classes populares terem que ingressar precocemente no mercado de trabalho, acontecendo assim, uma inserção de maneira precária nos postos de trabalho, por falta de formação profissional qualificada.

Diante da necessidade de empregabilidade dos jovens há uma preocupação do Estado com o processo de formação para a inserção no mercado de trabalho, uma preocupação com a Educação Profissional, que "se constitui no processo pelo qual os trabalhadores são formados para produzirem sua existência por meio de seu trabalho, o qual se volta para a produção de bens e 
serviços necessários socialmente" (RAMOS, 2012.p. 5). Contudo, sabemos que, muitos desses bens são inatingíveis para os jovens das classes populares; para os filhos dos trabalhadores.

Porém, a Educação Profissional não deve ser a única preocupação, mas deve ser considerada para os jovens, principalmente, no que tange ao acesso e a permanência à formação de base científica, cultural e tecnológica, e não apenas a formação para uma determinada profissão. Daí a importância da articulação da Educação Profissional à Educação Básica na formação dos jovens. Sendo assim, cabe ao Estado providenciar políticas públicas para que o jovem construa sua escolaridade, sua Educação Profissional e sua relação com o mundo do trabalho, garantindo as condições materiais para que o percurso dos jovens na educação formal não seja prejudicado pela necessidade de prover seu sustento e de seus familiares. E que, seja oferecido a eles uma educação que os tornem sujeitos autônomos e emancipados, e não apenas sujeitos tecnicamente formados para atender às necessidades do mercado capitalista.

Na conjuntura da 1a década do século XXI, especificamente, quando Luiz Inácio Lula da Silva assume a gestão do Brasil, em 2003, substituindo o Decreto no 2.208/97(BRASIL, 1997)1 pelo Decreto 5.154/042 (BRASIL, 2005), as políticas públicas para a Educação Profissional articuladas à Educação Básica tornaram-se mais coerentes com o projeto de desenvolvimento nacional que contestava o capitalismo em suas bases neoliberais. Embora não rompesse com essas em vários aspectos, sabe-se que a Educação Profissional ganhou o sentido de integração à Educação Básica. Isto foi considerado fundamental para a formação de base científica, cultural, tecnológica e profissional dos sujeitos jovens. Também neste contexto, a qualificação profissional assumiu relevância nas políticas para a Juventude, pois foram criados programas sociais pelo Governo Federal para a inclusão social de jovens no mundo do trabalho.

Na perspectiva de elaboração de políticas para os jovens, foi criado pela Lei 11.129/2005 e regulamentado pelo Decreto Presidencial no 5.490 de 14 de julho de2005, o Conselho Nacional de Juventude (CONJUVE). Este iniciou suas atividades em 02 de agosto do mesmo ano. O Conselho Nacional de Juventude expressa a relação entre gerações, etnias, religiões, regiões, orientações sexuais e gêneros atualizada em diversos tipos de organizações, redes e trajetórias profissionais.

Este Conselho busca o reconhecimento e a legitimidade do tema juventude perante os governos, a opinião pública e a sociedade. A partir desse reconhecimento, tornou-se possível impulsionar a formulação de políticas de acordo com as características e necessidades dos jovens, e a criação de programas voltados para este público. Também recomenda a Lei que sejam apresentadas medidas concretas para que todos os jovens possam ingressar e concluir o Ensino Médio na idade correta. Mas, mais de uma década após sua criação os problemas continuam, pois os Programas voltados para o atendimento aos jovens não tem alcançado os objetivos esperados e os desafios também continuam.

O Conselho Nacional de Juventude diferencia três tipos de medidas do Governo Federal com foco nos jovens:

\footnotetext{
${ }^{1}$ Sugere a separação da Educação profissional do Ensino Médio

${ }^{2}$ Sugere a modalidade integrada de Educação Profissional ao Ensino Médio
} 
Quadro 01-Três tipos de medidas do governo federal com foco nos jovens -2000-2010

\begin{tabular}{|c|c|c|}
\hline MEDIDAS & O QUE SÃO? & EXEMPLOS \\
\hline Políticas estruturais & $\begin{array}{l}\text { São políticas continuadas, } \\
\text { relacionadas à garantia de direitos } \\
\text { fundamentais. }\end{array}$ & $\begin{array}{l}\text { Ampliação do acesso ao Ensino Superior e } \\
\text { Ensino Médio; Ampliação do Ensino } \\
\text { Profissional; Educação do Campo, Expansão da } \\
\text { Educação de Jovens e Adultos. }\end{array}$ \\
\hline $\begin{array}{l}\text { Programas } \\
\text { governamentais }\end{array}$ & $\begin{array}{l}\text { Subordinados ou não às políticas } \\
\text { estruturais, com o objetivo de atuar } \\
\text { sobre uma realidade social } \\
\text { específica. }\end{array}$ & $\begin{array}{l}\text { Escola de Fábrica; Escola Aberta; Diversidade } \\
\text { na Universidade; Programa Nacional de } \\
\text { Inclusão de Jovens (PROJOVEM); Programa } \\
\text { Nacional de Estímulo ao Primeiro Emprego } \\
\text { (PNPE); Programa de Educação de Jovens e } \\
\text { Adultos (PROEJA); Fazendo Escola; Projeto } \\
\text { Rondon; Soldado Cidadão; Brasil Alfabetizado } \\
\text { (com foco em juventude); Programa } \\
\text { Universidade para Todos (PROUNI); Programa } \\
\text { de Apoio à Extensão Universitária para Políticas } \\
\text { Públicas (PROEXT); Programa Nacional de } \\
\text { Fortalecimento da Agricultura Familiar para os } \\
\text { jovens (PRONAF Jovem); Terra Negra; Agente } \\
\text { Jovem e Programa Brasil Profissionalizado. }\end{array}$ \\
\hline Ações & $\begin{array}{l}\text { São ações de curto prazo ou restritas } \\
\text { a um público específico. Articulam- } \\
\text { se ou não com as políticas } \\
\text { estruturais e os programas }\end{array}$ & $\begin{array}{l}\text { Consórcio Social da Juventude; Programa } \\
\text { Nacional do Livro para o Ensino Médio } \\
\text { (PNLEM); Pontos de Cultura (Cultura Viva); } \\
\text { Diversidade Sexual nas Escolas (Brasil sem } \\
\text { Homofobia). }\end{array}$ \\
\hline
\end{tabular}

Fonte: Elaboração dos autores, com base nas diretrizes e perspectivas de políticas educacionais para a juventude. Disponível em: http://library.fes.de/pdf-files/bueros/brasilien/05611.pdf.

As medidas apresentadas demonstram uma preocupação com as condições de vida dos jovens brasileiros, pois essas os apresenta como sujeitos de direito e protagonistas sociais, sendo, portanto, demandantes de políticas públicas. Os programas postos no Quadro 01, de acordo com as medidas governamentais foram criados e implementados durante a 1a década do século XXI, e contribuíram para o aumento da oferta de matrículas na Educação Básica, Ensino Superior e Educação Profissional, como apresentamos na Tabela 01 a seguir:

Tabela 01: Matrículas na Educação Profissional - 2002-2010

\begin{tabular}{|c|c|c|c|c|c|}
\hline \multirow{3}{*}{ Ano } & \multicolumn{5}{|c|}{ Matriculas na Educação Profissional } \\
\hline & \multicolumn{5}{|c|}{ Dependência Administrativa } \\
\hline & Total & Federal & Estadual & Municipal & Privada \\
\hline 2002 & 652.073 & 77.190 & 220.853 & 26.464 & 327.566 \\
\hline 2003 & 629.722 & 82.943 & 181.485 & 22.312 & 342.982 \\
\hline 2004 & 676.093 & 82.293 & 179.456 & 21.642 & 392.702 \\
\hline 2005 & 747.892 & 89.114 & 206.317 & 25.028 & 427.433 \\
\hline 2006 & 806.498 & 93.424 & 261.432 & 27.057 & 424.585 \\
\hline 2007 & 780.162 & 109.777 & 253.194 & 30.037 & 387.154 \\
\hline 2008 & 927.978 & 124.718 & 318.404 & 36.092 & 448.764 \\
\hline 2009 & 1.036 .945 & 147.947 & 355.688 & 34.016 & 499.294 \\
\hline 2010 & 1.140 .388 & 165.355 & 398.238 & 32.225 & 544.570 \\
\hline$\Delta \%$ 2002-2010 & 74,9 & 114,2 & 80,3 & 21,8 & 66,2 \\
\hline
\end{tabular}

Fonte: Tabela retirada do Resumo Técnico - Censo Escolar 2010, do INEP. Disponível em:http://download.inep.gov.br/download/censo/2010/divulgacao_censo2010_201210.pdf 
Nota-se, a partir da Tabela 01, que houve aumento nas matrículas da Educação Profissional, principalmente, na rede pública, considerando que apresentou um aumento em 2010 que representou 52\% dessas matrículas. (BRASIL, CENSO DA EDUCAÇÃO PROFISSIONAL, 2010).

De acordo com o Censo Escolar3 (2010) as matrículas na Educação Profissional ultrapassaram 900 mil em 2010, sendo as matrículas na oferta subsequente4 a que teve o maior número de participação, $62 \%$ no total dos matriculados. No entanto, na Rede Federal a Educação Profissional nas ofertas concomitante5ou integrada6 ao Ensino Médio teve uma participação de $61,8 \%$ do total de matrículas nesta rede. Na 1a década do século XXI a Rede Federal dobrou a oferta de matrícula na Educação Profissional, com um crescimento de $114 \%$ no período, isso significa maiores oportunidade de acesso à Educação Profissional articulada à Educação Básica, de forma gratuita. (BRASIL, CENSO DA EDUCAÇÃO PROFISSIONAL, 2010).

A Educação Profissional nos Estados brasileiros vem sendo construída num processo histórico cuja trajetória apresenta aproximações e diferenças nas dimensões que envolvem a própria concepção, a normatização e questões de ordem técnica e administrativa. (BATISTOLLI, GROSSI JR. e GARCIA, 2012. p. 196). Essa trajetória irregular tem afetado a vida dos jovens brasileiros que não tem condições de custear seus estudos, por essa razão a proposta que reverbera deste estudo é a de que a elaboração dessas políticas, para a educação e qualificação profissional dos jovens, não sejam somente definidas a partir de critérios econômicos, mas que tenham a participação dos jovens expondo suas necessidades e interesses de estudo e de trabalho.

\section{PROGRAMAS DE EDUCAÇÃO PROFISSIONAL ARTICULADOS À EDUCAÇÃO BÁSICA PARA OS JOVENS (2000- 2010)}

Como foi referido no tópico anterior, o contexto político da 1a década do século XXI permitiu a discussão sobre a integração da Educação Profissional ao Ensino Médio. Essa integração esteve orientada pelo estabelecimento da relação entre conhecimento e prática do trabalho. Assim, quando se trata de políticas para a Educação Profissional:

Seu horizonte deveria ser o de propiciar aos alunos o domínio dos fundamentos das técnicas diversificadas utilizadas na produção e não no mero adestramento em técnicas produtivas. Não se deveria, então, propor que o ensino médio formasse técnicos especializados, mas sim politécnicos. (FRIGOTTO, CIAVATTA E RAMOS, 2005, p.35).

Os autores enfatizam a necessidade de propiciar aos alunos um ensino que seja humanista, mas que contribua para o desenvolvimento dos sujeitos em suas capacidades de compreensão da totalidade social, situados historicamente em um mundo capitalista contraditório e excludente.

\footnotetext{
${ }^{3} \mathrm{O}$ Censo Escolar, realizado anualmente pelo Instituto Nacional de Estudos e Pesquisas Educacionais Anísio Teixeira, INEP, é o mais relevante e abrangente levantamento estatístico sobre a Educação Básica no país. Os dados coletados servem de fontes para a formulação de políticas e para reelaboração de programas.

${ }^{4}$ Oferecida aos alunos que já concluíram o Ensino Médio

${ }^{5}$ O aluno cursa a Educação Profissional ao mesmo tempo em que estuda o Ensino Médio. Com matrizes curriculares diferentes.

${ }^{6}$ Educação Profissional integrada ao Ensino Médio.
} 
Na conjuntura política dos primeiros 10 anos do século XXI, por meio de programas e ações políticas, se buscou a universalização do Ensino Médio a partir da integração dos eixos trabalho, ciência, tecnologia e cultura. Nesse sentido, foram implementados alguns programas que sugerem a integração dos conhecimentos da Educação Profissional com os conhecimentos da Educação Básica, principalmente na última etapa desta, qual seja no Ensino Médio.

Após a discussão sobre a necessidade e relevância dessa integração para a formação dos jovens brasileiros, especificamente dos jovens oriundos da classe dos trabalhadores, serão apresentados a seguir os programas de Educação Profissional articulados à Educação Básica executados na 1 a década do século XXI.

Quadro 2: Programas de Educação Profissional com a Educação Básica da 1ạ década do século XXI

\begin{tabular}{|l|l|}
\hline \multicolumn{1}{|c|}{ PROGRAMAS } & \multicolumn{1}{c|}{ OBJETIVOS } \\
\hline $\begin{array}{l}\text { Programa Nacional de } \\
\text { Inclusão de Jovens: } \\
\text { Educação, Qualificação e } \\
\begin{array}{l}\text { Ação Comunitária- } \\
\text { (PROJOVEM) (2005) }\end{array}\end{array}$ & $\begin{array}{l}\text { "Executar ações integradas que propicie aos jovens brasileiros, na forma de } \\
\text { curso, elevação do grau de escolaridade visando a conclusão do ensino } \\
\text { fundamental, qualificação profissional, voltada a estimula a inserção } \\
\text { produtiva cidadã e o desenvolvimento de ações comunitárias com praticas } \\
\text { de solidariedade, exercício da cidadania e intervenção na realidade local"( } \\
\text { BRASIL, 2005). }\end{array}$ \\
\hline $\begin{array}{l}\text { Programa de Educação } \\
\text { Profissional Integrada à } \\
\text { Educação Básica na } \\
\text { Modalidade de Jovens e } \\
\text { Adultos (PROEJA)- 2005 }\end{array}$ & $\begin{array}{l}\text { Resgatar e inserir na escola uma grande quantidade de jovens e adultos } \\
\text { que tiveram suas trajetórias educacionais interrompidas, oferecendo o } \\
\text { acesso a uma formação integral articulada à Educação Profissional Técnica } \\
\text { de Nível Médio. }\end{array}$ \\
\hline $\begin{array}{l}\text { Programa Brasil } \\
\text { Profissionalizado- 2007 }\end{array}$ & $\begin{array}{l}\text { Apoiar e fortalecer o desenvolvimento de propostas curriculares } \\
\text { inovadoras nas escolas de Ensino Médio, ampliando o tempo dos } \\
\text { estudantes na escola buscando garantir a formação integral com a inserção } \\
\text { de atividades que tornem o currículo mais dinâmico, atendendo também as } \\
\text { expectativas dos estudantes do Ensino Médio e às demandas da sociedade } \\
\text { contemporânea. }\end{array}$ \\
\hline
\end{tabular}

Fonte: Elaboração própria com base nas informações contidas no site oficial do MEC (www.mec.edu.br)

O Ensino Médio Integrado é outra política que vem sendo implantada desde 2005. De acordo com o site do Ministério da Educação e Cultura (MEC) mais de $R \$$ 1,5 bilhão já foi conveniado pelo Ministério da Educação para a implantação de Ensino Médio Integrado à Educação Profissional nos Estados. O dinheiro deve ser empregado em obras de infraestrutura, desenvolvimento de gestão, práticas pedagógicas e formação de professores.

Para Grabowski e Ribeiro (2010) a Educação Profissional, por ser modalidade que permite a transversalidade e a integração em todos os níveis de ensino, a partir do Ensino Fundamental foi a modalidade mais afetada pela proposta da nova LDB (art.39 a 42) nas regulamentações do Decreto 2.208/97 e do Decreto 5.154/05, pois foi definida como modalidade de educação e ensino que "conduz ao permanente desenvolvimento de aptidões para a vida produtiva, ao estar integrada às diferentes formas de educação, ao trabalho, à ciência e à tecnologia". (GRABOWSKI; RIBEIRO, 2010, p. 272).

Nesse sentido, a Educação Profissional deixa de ter um viés assistencialista atribuído somente à qualificação profissional. Esse é o caminho para a construção de uma sociedade igualitária, pois, essa concepção de Educação Profissional, a que propõe uma formação integral 
dos sujeitos, vai contra a concepção de uma educação economicista dependente do processo de reprodução do capital.

No entanto, apesar de se compreender que as políticas empreendidas e as medidas adotadas na 1 a década do século XXI tenham apresentado resultados positivos em alguns momentos, essas não foram suficientes para enfrentar o problema da falta de cobertura do Ensino Médio no Brasil.

As novas determinações do mundo social e produtivo, gerado pela globalização de mercados, colocam dois novos desafios para o Ensino Médio: a sua democratização e a formulação de outras concepções, que integrem formação científica e sócio-histórica à formação tecnológica e profissional dos jovens. A democratização não se basta na ampliação de vagas, mas exige espaços físicos, formação de professores e reestruturação curricular. Sobre a nova concepção, "tem-se clareza de que ela só será plenamente possível em uma sociedade em que todos desfrutem igualmente das mesmas condições de acesso aos bens materiais e culturais socialmente produzidos." (KUENZER, 2009.p. 35).

Nesse sentido, Oliveira (2012) afirma que a educação deve ser valorizada em virtude de valores que lhe dão o sentido de existência: a formação humana integral, que de acordo com Moura (2007), corresponde a formação de sujeitos competentes tecnicamente, mas também com a capacidade crítica, para que sejam autônomos e emancipados socialmente. Educação Básica e Profissional, assim como a Superior, "é um espaço- não o único, mas fundamental- para a elaboração de uma identidade agregadora de várias dimensões, sejam estas políticas, afetivas, físico-intelectuais ou econômicas." (OLIVEIRA, 2012.p. 97).

É no contexto econômico e social de globalização que aparece o desafio de oferecer uma formação geral e uma formação que permita a inserção dos sujeitos no mundo do trabalho, ou seja, uma formação humana integral, posto que essa formação se diferencia do que é proposto pelo mercado de trabalho, pois busca garantir a formação completa dos sujeitos. É preciso, portanto, pensar que na base da proposta da formação humana, há a superação da dualidade histórica entre formação básica e formação profissional necessária à formação dos jovens da classe trabalhadora.

\section{CONCLUSÕES}

Na realidade da sociedade brasileira os jovens das classes desfavorecidas economicamente precisam ingressar no mercado de trabalho, diante da necessidade de assumirem as responsabilidades ligadas à provisão do próprio sustento. Por esse motivo, são vários os jovens que não concluem a Educação Básica, ou tem negada a possibilidade de ingressar no Ensino Superior.

Diante disso, poderiam ser oferecidas aos jovens condições e oportunidades de acesso à Educação Profissional articulada à Educação Básica. Nesse sentido, foi discutido, neste artigo, a Educação Profissional para os jovens no Brasil, com ênfase nas políticas educacionais, articuladas à Educação Básica desenvolvidas na 1a década do século XXI nas quais se observou que ainda há problemas e desafios a serem superados.

Os programas de Educação Profissional articulados à Educação Básica apresentados são políticas públicas de educação, trabalho e qualificação para os jovens brasileiros, especificamente, 
para aqueles que estão em situação social e econômica vulneráveis. Esses programas apresentam os jovens como cidadãos, possibilitando que os mesmos tenham direito ao estudo, escolarização, qualificação profissional e participação social, contudo, ainda existem muitos desafios a serem enfrentados, pois o total de matrículas na Educação Profissional ainda é muito baixo no Brasil.

Para formulação de políticas públicas para a educação de jovens, é necessário aprofundar discussões sobre a relação existente entre educação e trabalho, assim como, organizar uma agenda de discussões entre os agentes sociais e os políticos os quais elaboram as políticas educacionais, para que observem a capacidade instalada, principalmente na Rede Federal de Ensino.

Diante do que foi apresentado ao longo do texto, defende-se que os programas de profissionalização para os jovens devem ser implementados de forma a contemplar atividades artísticas, culturais e tecnológicas. Que a Educação Profissional seja oferecida de forma integrada à Educação Básica. Assim, pode-se visualizar um tipo de ensino que permitiria a integração dos diferentes tipos de conhecimentos, produzidos e acumulados historicamente, com a formação profissional. Desse modo, quem sabe, poderia se ter a educação que interessa aos jovens brasileiros que vivem do trabalho e que gostariam de ser educados, no presente, para o mundo no qual vivem. Este talvez seja um dos maiores desafios para as políticas da juventude no Século XXI.

\section{REFERÊNCIAS}

1. AQUINO, Luseni Maria C. de. Introdução. A juventude como foco das políticas públicas. In: CASTRO, Jorge Abrahão de. et al (Org.). Juventude e políticas sociais no Brasil. Brasília: IPEA, 2009 p. 23-39.

2. ARAÚJO, Ronaldo Marcos de Lima. ALVES, João Paulo da Conceição.Juventude, Trabalho e Educação: questões de diversidade e classe das juventudes na Amazônia. Disponível em: http://www.anpae.org.br/simposio26/1comunicacoes/RonaldoMarcosdeLimaAraujoComunicacaoOral-int.pdf. Acesso em: agosto de 2014.

3. AZEVEDO, Janete Lins de. Programas federais para a gestão da educação básica: continuidades e mudanças. RBPAE, Porto Alegre, v. 25, n. 2, p.211-232, maio/ ag. 2009.

4. BATISTTOTI, Édna Corrêa; JUNIOR, Geraldo Grossi; GARCIA, Sandra Regina de Oliveira. As redes estaduais de ensino e a construção de uma política nacional de educação profissional. IN: Moll, Jaqueline (Org.). Educação profissional e tecnológica no Brasil contemporâneo: desafios, tensões e possibilidades. Porto Alegre: Armed, 2010.

5. BRASIL, Programa Brasil profissionalizado. Manual de orientação de preenchimento da situação escolar. Disponível em: http://portal.mec.gov.br/index.php?option=com_content\& view=article\&id=13790\&ltemid=993. Acesso em junho de 2014.

6. _. Programa de Educação profissional Integrada à Educação Básica na Modalidade de Jovens e Adultos. Disponível em: http://portal.mec.gov.br.Acesso em fevereiro de 2014.

7. . Programa Ensino Médio Inovador Documento Orientador (2014). Disponível em: www.mec.gov.br. Acesso em fevereiro de 2014.

$8 . \quad$. Decreto $\mathrm{n}$ - 5.154, de 23 de julho de 2004. Regulamenta o $\S 20$ do art. 36 e os arts. 39 a 41 da Lei no 9.394, de 20 de dezembro de 1996, que estabelece as diretrizes e bases da educação nacional. Brasília, DF: 23 de julho de 2004.

9. ___. Decreto №. 2.208, de 17 de abril de 1997. Regulamenta o $\S 20$ do art. 36 e os artigos 39 a 42 da Lei federal no. 9.394/96. Brasília, DF: 17 de abril de 1997. 
10. FRIGOTTO, Gaudêncio; CIAVATTA, Maria; RAMOS, Marise (Org.). Ensino médio integrado: concepções e contradições. São Paulo Cortez, 2005.

11. GRABOWSKI, Gabriel; RIBEIRO, Jorge Alberto Rosa. Reforma, legislação e financiamento da educação profissional no Brasil. In: MOLL, Jaqueline (Org.). Educação profissional e tecnológica no Brasil contemporâneo: Desafios, tensões e possibilidades. Porto Alegre: Artmed, 2010, 312p.

12. INSTITUTO NACIONAL DE ESTUDOS E PESQUISAS EDUCACIONAIS ANÍSIO Teixeira. Censo da Educação Profissional 2010. Brasília. Disponível em: http://download.inep.gov.br/download/ censo/2010/divulgacao_censo2010_201210.pdf

13. KUENZER, Acácia Zeneida (Org.). Ensino médio: construindo uma proposta para os que vivem do trabalho. 3. ed. São Paulo: Cortez, 2009.

14. Ministério da Educação. Instituto Nacional de Estudos e Pesquisas Educacionais Anísio Teixeira. Sinopse Estatística da Educação Básica, 2009. Brasília, DF, 2009. Disponível em: <http://portal.inep.gov.br/basica censo-escolar-sinopse-sinopse>. Acesso em: 6 nov. 2014.

15. MOURA, Dante Henrique. Educação básica e educação profissional e tecnológica: dualidade histórica e perspectivas de integração. Anais. 30a Reunião Anual da ANPED. Caxambu: ANPED, 2007.

16. OLIVEIRA, Ramon de. (Org.) Jovens, ensino médio e educação profissional: políticas públicas em debate. Campinas: 2012.

17. RAMOS, Marise. Educação tecnológica como política de Estado. In: OLIVEIRA, Ramon de. (Org.) Jovens, ensino médio e educação profissional: políticas públicas em debate. Campinas: 2012.

18. SANTOS, Pablo Silva Machado Bispo. Guia prático da política educacional no Brasil: ações, planos, programas e impactos. São Paulo: Cengage Learning, 2012.

19. VENTURI, Gustavo; ABRAMO Helena. Juventude, política e cultura. Publicado em Teoria e Debate, revista da Fundação Perseu Abramo, no 45, jul/ago/set. São Paulo, 2000. 